\title{
BEHAVIOUR RESEARCH AND THERAPY
}

\author{
INCORPORATING Behavioral Assessment
}

AN INTERNATIONAL MULTI-DISCIPLINARY JOURNAL

Editor-in-Chief: S. RACHMAN, Dept of Psychology, University of British Columbia, Vancouver, British Columbia, Canada

Associate Editor: S. TAYLOR, Department of Psychiatry, The University of British Columbia, Vancouver, British Columbia, Canada

The journal publishes scientific papers pertaining to abnormal behaviour and experiences, and their modification, and to medical psychology. The assessment of abnormal behaviour and experiences, and how they change and under what conditions, has always been within the scope of Behaviour Research and Therapy, and we have now incorporated Behavioral Assessment. Approximately one-quarter of this expanded journal will be devoted specifically to assessment. In keeping with the important scientific and clinical developments of the past few years, the scope of the journal was widened to include work on behavioural medicine/medical psychology. Articles on these subjects are welcomed.

\section{A Selection of Papers}

From Behaviour Research and Therapy

R. P. SWINSON, B. J. COX, I. D. SHULMAN, K. KUCH \& C. B. WOSzCZYNA (Canada), Medication use and the assessment of agoraphobic avoidance.

A. STEPTOE (UK) \& C. VÖGELE (FRG), Individual differences in the perception of bodily sensations: the role of trait anxiety and coping style.

E. B. BLANCHARD, L. SCHARFF, A. PAYNE, S. P. SCHWARZ, J. M. SULS \&

H. MALAMOOD (USA), Prediction of outcome from cognitive-behavioral treatment of irritable bowel syndrome.

From Behavioral Assessment

V. M. FOLLETTE (USA), Contributions to the behavioral assessment of verbal and physical aggression in intimate relationships.

G. MORAN (Canada), J. E. DUMAS (USA) \& D. K SYMONS (Canada), Approaches to sequential analysis and the description of contingency in behavioral interaction.

Indexed/Abstracted in: Biosis Data, CABS, Curr Cont Soc Sci Cit Indx,Curr Cont/Soc \& Beh Sci, Excerp Med, Ind Med, LLBA, MEDLINE, PASCAL-CNRS Data, Psychol Abstr, PsycSCAN, PsycINFO, PsycLIT, Social Work Res \& Abstr

(00265)

Subscription Information

1993: Volume 31 ( 8 issues)

Annual subscription (1993)

$£ 268.00$

US\$429.00*

ISSN: 0005-7967

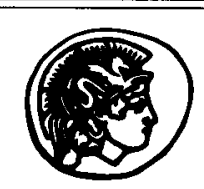

\section{PERGAMON PRESS}

Pergamon Press Ltd, Headington Hill Hall, Oxford OX3 OBW, UK

Pergamon Press Inc., 660 White Plains Road, Tarrytown, NY 10591-5153, USA

A member of the Elsevier Science Publishing Group

First price quoted is definitive. Prices include postage and insurance. *Asterisked price is quoted for convenience only and is subject to exchange rate fluctuation. 


\section{INSTRUCTIONS TO CONTRIBUTORS}

Behaviour Change is a quarterly journal devoted to the publication of research involving the application of behavioural and cognitive-behavioural principles and techniques to the assessment and treatment of health, social, organisational, community and educational problems. It publishes original empirical studies using either single subject or group comparison methodologies, review articles, case studies, brief technical and clinical notes, invited book reviews, and special issues dealing with particular topics in depth.

MANUSCRIPTS SHOULD BE SUBMITTED TO:

Matthew R. Sanders, Ph. D.,

Department of Psychiatry,

The University of Queensland, Clinical Sciences Building,

Royal Brisbane Hospital,

Herston, Q 4029, Australia.

\section{Preparation of manuscripts}

Four copies of each manuscript, prepared according to the Publication Manual of the American Psychological Association, 3rd edition (1983) should be sent to the editor with a cover letter requesting review of the manuscript. Spelling should conform to the Macquarie Dictionary. The cover letter should contain a statement indicating that the manuscript has not been published elsewhere nor is it currently under editorial review.

\section{Cover page}

The manuscript must have a cover page with the title of the article, author(s) names and affiliation, a running head and at the bottom of the paper the name and postal address of the person to whom correspondence, proofs and reprint requests should be sent. To facilitate anonymous review the second page should include the title of the article without author identification.

\section{Abstract}

Articles should be accompanied by an abstract which should not exceed 200 words. The abstract should follow the title page on a separate page. It should provide a brief overview of the aims, method and major findings and should not refer to the body of the text in the abstract.

3. Typing

Manuscripts should be typed on A4, double spaced, with $4 \mathrm{~cm}$ wide margins. If a manuscript is accepted for publication authors who have prepared the manuscript on an IBM-compatible PC or Macintosh computer should submit a copy of the paper on disk in addition to the final hard copy version. Acceptable word processing formats are: Word Perfect, Microsoft, Multimate, Wordstar, Office Writer, Microsoft Works, Microsoft Word, Macwrite, and ASCII. Disks may be supplied in either 3.5 inch or 5.25 inch formats. The word processing program used and version number, are to be specified in writing on the title page of the final accepted manuscript. Disks will be returned after use.

4. Tables and Figures

Tables require consecutive numbering and should be referenced by number in the text. Tables should be typed on separate sheets. Indicate in the text the approximate location of tables and figures.

5. Proofs and Reprints

Page proofs will be sent to the corresponding author for correction. Excessive alteration of the manuscript, as distinct from correction of errors in reproduction are not permitted and will be charged to the author(s). Authors will receive 25 copies of their paper free of charge. Additional reprints may be ordered when the proofs are returned. 
Problem Behaviour as Communication

V. Mark Durand

Clinicians Ought to View Anger Contextually

Raymond W. Novaco

Recent Developments in Posttraumatic Stress Disorder

Mark Creamer

Role of Cognitive Therapy in the Management of Chronic Pain

Susan H. Spence

"Hey Dad, Watch Me": The Effects of Training a Child to Teach Pain Management Skills to a Parent With Recurrent Headaches

Grant J. Devilly and Matthew R. Sanders

Social Skills Training for Abused Girls: Interpersonal Skills Training for Sexually Abused Girls

Mark D. Weist, Kathryn Vannatta, Kathleen K. Wayland and Chianti Y. Jackson

Book Reviews 